\title{
Review
}

Medical Principles
and Practice

Med Princ Pract 2015;24(suppl 1):14-28

Received: October 31, 2013

DOI: $10.1159 / 000362416$

Accepted: March 24, 2014

Published online: May 10, 2014

\section{Photodynamic Therapy: Current Status and Future Directions}

\author{
Ludmil Benov \\ Department of Biochemistry, Faculty of Medicine, Health Sciences Centre, Kuwait University, \\ Jabriya, Kuwait
}

\section{Key Words}

Photodynamic therapy · Photosensitizer · Porphyrin .

Singlet oxygen $\cdot$ Hydroxyl radical $\cdot$ Superoxide

\begin{abstract}
Photodynamic therapy (PDT) is a minimally invasive therapeutic modality used for the management of a variety of cancers and benign diseases. The destruction of unwanted cells and tissues in PDT is achieved by the use of visible or nearinfrared radiation to activate a light-absorbing compound (a photosensitizer, PS), which, in the presence of molecular oxygen, leads to the production of singlet oxygen and other reactive oxygen species. These cytotoxic species damage and kill target cells. The development of new PSs with properties optimized for PDT applications is crucial for the improvement of the therapeutic outcome. This review outlines the principles of PDT and discusses the relationship between the structure and physicochemical properties of a PS, its cellular uptake and subcellular localization, and its effect on PDT outcome and efficacy.
\end{abstract}

\section{Introduction}

Photodynamic therapy (PDT) is a noninvasive, highly selective method for the destruction of unwanted cells and tissues. It was clinically approved more than a quarter of a century ago for the treatment of a small number of selected tumors [1] and has expanded tremendously to include areas of application as diverse as cardiology [2,3], urology [4], immunology [5], ophthalmology [6,7], dentistry $[8,9]$, dermatology $[10,11]$ and cosmetics $[12,13]$. Antimicrobial/antiviral PDT has been successfully used for the treatment of viral infections $[14,15]$, against antibiotic-resistant bacterial $[16,17]$ and fungal strains [18-20], for the inactivation of pathogens in blood products [21], for water sterilization $[22,23]$ and for disinfection and sanitation of surfaces $[24,25]$. The photodynamic process is successfully used for drug delivery and the release of endocytosed macromolecules in the cytosol $[26,27]$.

Among the main advantages of PDT is its high selectivity. It is based on the requirement for the simultaneous presence of three components, photosensitizer (PS), molecular oxygen, and visible or near-infrared (NIR) light, none of which is toxic or cell/tissue damaging by itself. Ideally, the PS is taken up and accumulates preferentially in the targeted cells. Because the PS is harmless in the absence 
of light, generalized toxicity in PDT is avoided by illuminating only the desired area. A PS absorbs light energy and transfers it to other nonabsorbing molecules. Such energy or electron transfer generates highly reactive species, which kill the targeted cells, damage tumor-associated vasculature and activate an antitumor immune response.

\section{Mechanism of the Photodynamic Action}

PSs are substances with a particular arrangement of electrons in their molecular orbitals. Like almost all molecules, at ground (singlet) state, PSs have couples of electrons with opposite spins in low-energy molecular orbitals. The absorption of light with the appropriate wavelength lifts an electron to a high-energy orbital without changing its spin. This is a short-lived (nanoseconds) excited singlet $\left(S_{1}\right)$ state and the PS can lose its energy and return to the ground state by emitting light (fluorescence) or heat. Alternatively, the $S_{1}$ state can undergo a process known as intersystem crossing, where the spin of the excited electron is inverted. This inversion of the electron spin is the reason for the relatively long life (microseconds) of the excited triplet $\left(\mathrm{T}_{1}\right)$ state. Radiative triplet-tosinglet transition is forbidden because it requires a change of the electron spin, which is a slow process [28]. From the $\mathrm{T}_{1}$ state, the PS can relax back to the ground state by emitting light (phosphorescence) or by transferring energy to another molecule. It can also lose energy through internal conversion or radiationless transitions during collisions with other molecules. The longer the life of the PS in the $T_{1}$ state, the higher are the chances that it will encounter a collision with another molecule, ending up with the production of chemically reactive species.

\section{Type I and Type II Processes}

While in a $\mathrm{T}_{1}$ state, a PS can be involved in two types of processes (fig. 1). In a type I process, the PS in a $T_{1}$ state abstracts an electron from a reducing molecule in its vicinity. Among such electron-donating molecules are reduced NADPH, guanine in nucleic acids, and tryptophan and tyrosine in proteins. As a result, a pair of radical anion $\left(\mathrm{PS}^{-} \cdot\right.$ ) and radical cations (biomolecule ${ }^{+}$) are formed. In an aerobic environment, the PS radical anion donates its extra electron to $\mathrm{O}_{2}$, producing a superoxide anion radical $\left(\mathrm{O}_{2}^{-} \cdot\right)$ and restoring the PS [29].

Superoxide can act as either a univalent oxidant or a reductant. It can oxidize small molecules such as sulfite, tetrahydroflavins, leukoflavins, catecholamines, the enediolate tautomers of sugars, and other good reductants

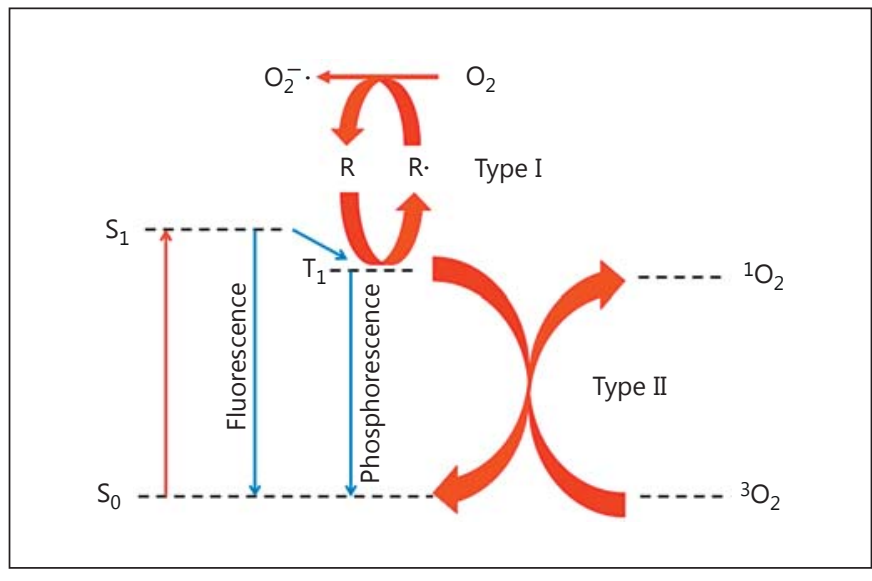

Fig. 1. Photoexcitation and participation of a PS in type I and type II processes.

[30], but it does not react directly with nucleic acids, lipids or carbohydrates [31]. The superoxide radical, however, can react at almost diffusion-limited rates $\left(\mathrm{k} \geq 10^{9} \mathrm{M}^{-1} \mathrm{~s}^{-1}\right)$ with other biologically relevant radicals, releasing potentially toxic cell-damaging products including organic hydroperoxides and quinones [32]. Among such radicals are nitric oxide (NO•) and the phenoxyl radicals generated by one-electron oxidation of phenols. In biosystems, the most abundant phenol is the amino acid tyrosine. The tyrosyl radical reacts with superoxide with a rate constant of $1.5 \times 10^{9} \mathrm{M}^{-1} \mathrm{~s}^{-1}$ [33]. It has been suggested that hydrogen bonding to an amine group increases the electrophilicity of $\mathrm{O}_{2}^{-}$. and the reduction potential of the $\mathrm{O}_{2} / \mathrm{O}_{2}{ }^{-}$. couple, which results in a dramatic increase of $\mathrm{O}_{2}{ }^{-} \cdot$ reactivity [34]. Another biologically important radical reacting with superoxide at an almost diffusion-limited rate $(\mathrm{k}$ $\left.\sim 3 \times 10^{9} \mathrm{M}^{-1} \mathrm{~s}^{-1}\right)$ is the guanine neutral radical $[\mathrm{G}(-\mathrm{H}) \cdot]$. Reactions of $\mathrm{O}_{2}^{-}$- with $\mathrm{G}(-\mathrm{H})$ - formed in polynucleotides $\left(\mathrm{k}=4.7 \times 10^{8} \mathrm{M}^{-1} \mathrm{~s}^{-1}\right)$ results in the accumulation of oxidatively modified guanine bases [35]. Reaction of superoxide with nitric oxide $(\mathrm{NO} \cdot)\left(\mathrm{k} \sim 4-6 \times 10^{9} \mathrm{M}^{-1} \mathrm{~s}^{-1}\right)$ produces a strong oxidant, peroxynitrite $\left(\mathrm{ONOO}^{-}\right)[36$, 37]. Peroxynitrite in turn can react with $\mathrm{CO}_{2}$ and bicarbonates $\left(\mathrm{k} \sim 3 \times 10^{4} \mathrm{M}^{-1} \mathrm{~s}^{-1}\right)$ [38] to yield nitrosoperoxycarbonate, a precursor of the carbonate radical anion $\left(\mathrm{CO}_{3}{ }^{-} \cdot\right)$ [39]. The carbonate radical anion is a one-electron oxidant capable of abstracting electrons from tyrosine and tryptophan [40]. In addition to reacting with other free radicals, superoxide is capable of oxidizing [4Fe-4S] clusters of proteins [41]. Such proteins are mainly dehydratases and Krebs cycle enzymes, and destruction of their [4Fe-4S] clusters has deleterious consequences. 
First, it inactivates these enzymes, which impairs the Krebs cycle and hence aerobic energy production and biosynthetic pathways that depend on such enzymes. Second, the iron that is released from the $[4 \mathrm{Fe}-4 \mathrm{~S}]$ clusters acts as a catalyst of $\mathrm{H}_{2} \mathrm{O}_{2}$ decomposition in the Fenton reaction, generating the powerful oxidant hydroxyl radical $(\mathrm{HO} \cdot)[42,43]$. The $\mathrm{Fe}^{2+}$ released from the [4Fe-4S] clusters would bind to anionic molecules including proteins, nucleic acids, lipids and other cell membrane components and would be kept in a reduced $\mathrm{Fe}^{2+}$ state by cellular reductants. Hydrogen peroxide, which is relatively stable and can diffuse across membranes, would reach $\mathrm{Fe}^{2+}$ bound to biomolecules, and $\mathrm{HO}$ - would be generated at the spot [44]. In addition to the Fenton reaction, $\mathrm{HO}$. can be photogenerated in a reaction where $\mathrm{H}_{2} \mathrm{O}_{2}$ is reduced by the PS radical anion [29]:

$$
\mathrm{H}_{2} \mathrm{O}_{2}+\mathrm{PS}^{-} \cdot \rightarrow \mathrm{HO} \cdot+\mathrm{OH}^{-}+\mathrm{PS}
$$

Due to its extremely high reactivity, $\mathrm{HO}$ - would damage targets it encounters at the site of its formation [45].

In type II photoreaction, the $\mathrm{T}_{1}$ state of the PS transfers its energy directly to molecular oxygen, itself a triplet in the ground state $\left({ }^{3} \mathrm{O}_{2}\right)$. This energy not only promotes one of the two unpaired electrons of ${ }^{3} \mathrm{O}_{2}$ to a high-energy orbital, but also inverts its spin, converting ground state molecular oxygen into singlet oxygen $\left({ }^{1} \mathrm{O}_{2}\right)$. Energy transfer to yield ${ }^{1} \mathrm{O}_{2}$ (type II) competes with electron transfer (type I), and it is believed that most PSs generate both ${ }^{1} \mathrm{O}_{2}$ and radicals. Because energy transfer to $\mathrm{O}_{2}$ occurs at a higher rate $\left(\mathrm{k} \approx 1-3 \times 10^{9} \mathrm{M}^{-1} \mathrm{~s}^{-1}\right)$ than electron transfer (e.g. to give $\mathrm{O}_{2}^{-} \cdot$, estimated as $\mathrm{k} \leq 1 \times 10^{7} \mathrm{M}^{-1} \mathrm{~s}^{-1}$ ) [46], and ${ }^{1} \mathrm{O}_{2}$ is more reactive than $\mathrm{O}_{2}^{-} \cdot$, singlet oxygen is considered the primary damaging species in PDT. In addition, biological systems are enzymatically protected against superoxide, but antioxidant enzymes that eliminate ${ }^{1} \mathrm{O}_{2}$ have not evolved, presumably because of its short lifetime.

Molecular oxygen has two $S_{1}$ states, denoted as ${ }^{1} \Delta_{\mathrm{g}}$ and ${ }^{1} \Sigma_{\mathrm{g}}$. These two states differ by the structure of the $\pi$-antibonding orbitals and by their energetic levels -95 $\mathrm{kJ} / \mathrm{mol}(22.5 \mathrm{kcal} / \mathrm{mol})$ versus $158 \mathrm{~kJ} / \mathrm{mol}(37.5 \mathrm{kcal} \mathrm{mol})$ above the ground state, respectively [45] (fig. 2). The higher energy excited state of ${ }^{1} \mathrm{O}_{2}\left({ }^{1} \Sigma_{\mathrm{g}}\right)$ is very short-lived due to a spin-allowed transition to the ${ }^{1} \Delta_{\mathrm{g}}$ state. The lifetime of the ${ }^{1} \Delta_{\mathrm{g}}$ state is determined by two processes: physical quenching, where the excess energy of ${ }^{1} \mathrm{O}_{2}$ is transferred to another molecule without the formation of products and the consumption of $\mathrm{O}_{2}$, and chemical quenching, which is a chemical reaction between ${ }^{1} \mathrm{O}_{2}$ and another molecule, generating identifiable products [47].



Fig. 2. Schematic representation of the electron configuration and energetic levels of ground and excited molecular oxygen states.

The presence of electrons with opposite spins, which removes the spin restriction typical for triplet oxygen [45], makes singlet oxygen highly reactive. It is an electrophile, oxidizing substrates that are not reacting with triplet oxygen. Singlet oxygen reacts rapidly with unsaturated carbon-carbon bonds and neutral nucleophiles such as sulfides and amines, as well as with anions [47], producing peroxides as initial products [28]. The decomposition of peroxides in turn generates radicals that can initiate a variety of chemical reactions, ultimately generating biologically active products.

In a biological environment, the lifetime of ${ }^{1} \mathrm{O}_{2}$ is limited by both physical and chemical quenching. As a result of physical quenching, the lifespan of ${ }^{1} \mathrm{O}_{2}$ in pure water is only about $4 \mu \mathrm{s}$ [48], but in cells it is shorter due to the contribution of chemical quenching [49]. Even if chemical quenching does not occur, the maximal length ${ }^{1} \mathrm{O}_{2}$ can travel would not exceed $150 \mathrm{~nm}$ [49]. This is an extremely short distance. It is much smaller than the size of an average mammalian cell $(10-30 \mu \mathrm{m})$ and even than the size of most cellular organelles. The short lifetime of ${ }^{1} \mathrm{O}_{2}$ makes localization of the PS a key factor in determining which cellular structures will be damaged and, as a consequence, the outcome of the PDT treatment.

\section{Photodynamic Targets at the Molecular Level}

Cells contain a variety of biomolecules that are potential substrates for oxidation by ${ }^{1} \mathrm{O}_{2}$ and other reactive species generated by PDT. In principle, the probability of such species reacting with a potential target depends on the distance between the PS and the target, the abundance of the target and the specific reaction rate constants. Singlet oxygen is considered the main damaging factor in PDT, but PSs operating mainly by the type I mechanism can also be highly effective [50]. PSs rarely 
participate only in type I or type II processes; therefore, photodynamic activation usually generates a mixture of ${ }^{1} \mathrm{O}_{2}$ and radicals [51]. Recent studies suggest that high PDT efficacy results from a synergistic action of species generated by type I and type II reactions $\left(\mathrm{O}_{2}^{-} \cdot \mathrm{HO} \cdot \mathrm{H} d\right.$ ${ }^{1} \mathrm{O}_{2}$ ) [52-54].

\section{Proteins}

Due to their abundance and relatively high rate constants for reactions with ${ }^{1} \mathrm{O}_{2}$ and other reactive oxygen species (ROS), proteins are regarded as a main photodynamic target. Amino acid residues differ dramatically with respect to rate constants for reaction with ${ }^{1} \mathrm{O}_{2}$. This results in selective damage to particular amino acid side chains. Under physiological conditions, cysteine, methionine, tyrosine, histidine and tryptophan react with ${ }^{1} \mathrm{O}_{2}$ at rates $>10^{7} \mathrm{M}^{-1} \mathrm{~s}^{-1}[46]$. These amino acid residues are primary sites of oxidative modification of proteins. The reaction mechanisms involved are complex and lead to a number of final products [55]. Cysteine and methionine are oxidized mainly to sulfoxides, histidine yields a thermally unstable endoperoxide, tryptophan produces $\mathrm{N}$ formylkynurenine, and tyrosine can undergo phenolic oxidative coupling. In the $\mathrm{pH}$ range of $7.0-8.5$, protein sulfhydryl groups are the most sensitive to photooxidation, followed by histidine, tryptophan and tyrosine. Abstraction of a hydrogen atom from cysteine residues produces a thiyl radical that will cross-link to a second thiyl radical and form disulfide bridges.

The hydroxyl radical, in contrast, reacts with most amino acids at diffusion-controlled rates [56]. Therefore, protein damage by $\mathrm{HO}$ - depends on the concentration of the target and the reactivity of initially formed products. For example, oxidation of tyrosine by the hydroxyl radical generates a tyrosyl radical [57]. As mentioned earlier, the tyrosyl radical reacts with $\mathrm{O}_{2}^{-} \cdot$ at an almost diffusionlimited rate [33]. Such reaction leads to either regeneration of tyrosine or the addition of $\mathrm{O}_{2}{ }^{-}$. to form tyrosine hydroperoxide $[58,59]$. In proteins, the formation of tyrosine hydroperoxide is favored when the tyrosine is at the N-terminus [58]. It has been suggested that hydrogen bonding of $\mathrm{O}_{2}^{-} \cdot$ to an amine group favors the addition reaction, thereby promoting the formation of tyrosine hydroperoxide [34]. Thus, without directly reacting with amino acid residues, $\mathrm{O}_{2}^{-} \cdot$ contributes to protein damage by releasing $\mathrm{Fe}$ from $[4 \mathrm{Fe}-4 \mathrm{~S}]$ clusters, participating in reactions with free-radical intermediates and generating $\mathrm{ONOO}^{-}$. Peroxynitrite reacts directly with sulfur-containing amino acids [60] and is a source of the highly oxidative carbonate radical [38].

Photodynamic Therapy

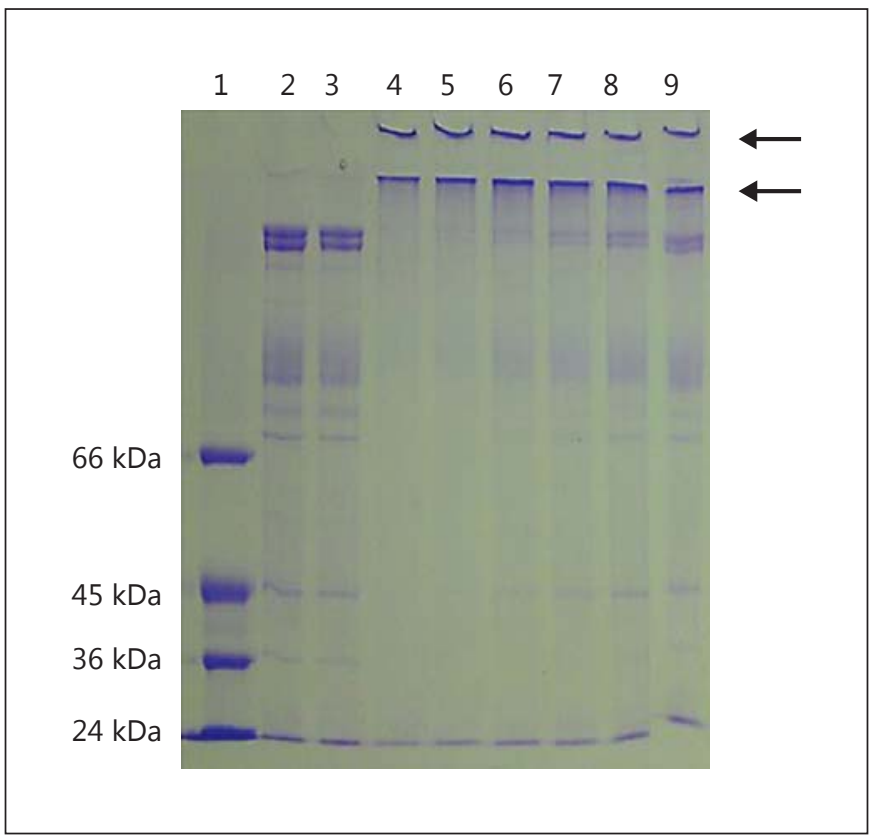

Fig. 3. Photo-induced cross-linking of erythrocyte membrane proteins. Hemoglobin-free erythrocyte membranes were illuminated for $30 \mathrm{~min}$ in the presence of $\mathrm{Zn}$ (II) meso-tetrakis( $\mathrm{N}$-butylpyiridinium-2-yl)porphyrin $\left(\mathrm{ZnTnBu}-2-\mathrm{PyP}^{4+}\right)$. Proteins were separated by sodium dodecyl sulfate gel electrophoresis and stained with Coomassie brilliant blue. Lanes: 1 - molecular weight markers; 2 - untreated erythrocyte membranes; 3 - dark control (incubated

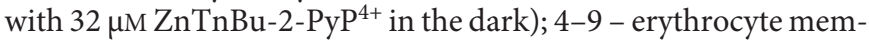
branes illuminated in the presence of different concentrations of ZnTnBu-2-PyP ${ }^{4+}$ (lanes: 4-32 $\mu \mathrm{M} ; 5-16 \mu \mathrm{M} ; 6-8 \mu \mathrm{M} ; 7-4 \mu \mathrm{M} ; 8-2$ $\mu \mathrm{M} ; 9-1 \mu \mathrm{M})$. Arrows point to protein aggregates.

Besides photooxidation of amino acid residues, other chemical modifications of proteins can take place [61]. They include PS/protein photo-binding and protein cross-linking through the coupling of two tyrosine units. Covalent cross-linking, which is regarded as a secondary reaction between photooxidation products of susceptible amino acid residues and other groups in the protein [62], leads to the formation of molecular aggregates (fig. 3).

Modification of an individual protein depends not only on the content but also on the position of vulnerable amino acid residues in the folded protein. Therefore, proteins differ substantially in their susceptibility to PDT damage. An additional factor, which affects protein damage in PDT, is the proximity of the PS to vulnerable sites [61], which in turn depends on PS localization.

As a consequence of photo-induced modifications, proteins lose their catalytic [63], cell signaling and oth- 
er essential functions, which ultimately leads to cell death (reviewed in detail by Pattison et al. [51]).

\section{PDT-Induced Lipid Peroxidation}

Lipids are less abundant than proteins, but a high content of unsaturated fatty acids, especially in biomembranes, makes membranous organelles and plasma membrane prime targets for photogenerated ${ }^{1} \mathrm{O}_{2}$ and other ROS [64]. The rates of reaction of singlet oxygen with unsaturated fatty acids are in the range of $0.74-2.4 \times 10^{5}$ $\mathrm{M}^{-1} \mathrm{~s}^{-1}$ and depend on the number of double bonds in the unsaturated fatty acids [65]. An additional factor, which contributes to PDT-induced lipid damage, is the high solubility of oxygen in lipids. Consequently, in its excited state, a PS localized in a lipid environment has a higher chance than in water to encounter $\mathrm{O}_{2}$ and to produce ${ }^{1} \mathrm{O}_{2}$ and oxygen-derived radicals. In contrast to radicals, which induce lipid peroxidation via hydrogen abstraction, ${ }^{1} \mathrm{O}_{2}$ can add directly to unsaturated fatty acids, generating lipid peroxides [66]. In the presence of traces of transition metals, lipid peroxides decompose, giving rise to alkoxyl and peroxyl radicals [67]. These radicals initiate free-radical chain reactions, which destroy the lipid bilayer of biomembranes and generate chemically reactive and biologically active products [68]. Thus, the consequences of lipid peroxidation are not limited to the direct damage of lipids, but include secondary modifications of proteins and polynucleotides [69]. In addition to affecting membrane functions [70], lipid peroxidation can lead to alterations in metabolism and cell signaling [71-74], resulting ultimately in cell death (for a detailed review see Girotti and Kriska [66]).

\section{Photosensitized Modification of Nucleic Acids}

Oxidatively generated DNA damage is among the causes of cell death in PDT. It can be mediated by oneelectron oxidation, $\mathrm{O}_{2}{ }^{-} \cdot / \mathrm{HO} \cdot$ and ${ }^{1} \mathrm{O}_{2}[69,75]$.

Direct one-electron oxidation occurs when an excited $\mathrm{PS}$ in a $\mathrm{T}_{1}$ state abstracts an electron/hydrogen atom from a DNA base [76]. Among the bases, guanine is particularly vulnerable due to its low ionization potential [77]. A guanine cation radical $\left(\mathrm{G}^{+} \cdot\right)$ is the immediate product. It can be converted to 8-oxo-7,8-dihydro-2'-deoxyguanosine and 2,6-diamino-4-hydroxy-5-formamidopyrimidine by competing one-electron oxidation and reduction reactions $[77,78]$ or is deprotonated to a highly reactive guanine radical, $\mathrm{Gua}(-\mathrm{H}) \cdot$. In an addition reaction with $\mathrm{O}_{2}^{-} \cdot$, Gua $(-\mathrm{H}) \cdot$ is converted to 2,2,4-triamino-5(2H)oxazolone $[77,78]$. The guanine cation radical can react with lysine, arginine and serine in proteins in a nucleo- philic addition reaction, giving rise to DNA-protein cross-links [75].

The most damaging among the ROS generated by the type I photo process is the hydroxyl radical, which indiscriminately reacts with all DNA constituents at diffusionlimited rates. The main way that $\mathrm{HO}$ - causes base modifications is by addition to double bonds [79]. This reaction competes with hydrogen abstraction by $\mathrm{HO}$ - from the methyl group of thymine and the 2-amino group of guanine [79]. Hydrogen abstraction from deoxyribose DNA backbone initiates reactions, causing DNA strand breaks $[75,80]$.

In contrast to $\mathrm{HO} \cdot$, singlet oxygen $\left({ }^{1} \Delta_{\mathrm{g}}\right.$ state $)$ is a highly selective DNA modifier [81]. Its prime target is guanine [79] $\left(\mathrm{k}=5 \times 10^{6} \mathrm{M}^{-1} \mathrm{~s}^{-1}\right.$ [82]), which through a series of reactions is converted into 8-oxo-7,8-dihydro-2' deoxyguanosine [83], a specific ${ }^{1} \mathrm{O}_{2}$ oxidation product [78] that can be detected after PDT treatment [84]. Since ${ }^{1} \mathrm{O}_{2}$ does not react with 2-deoxyribose, it cannot cut the DNA backbone, and previously reported formation of DNA nicks can be explained by secondary oxidation of 8-oxo-7,8-dihydro-2'-deoxyguanosine by ${ }^{1} \mathrm{O}_{2}$ [77]. Details about reactive species, mechanisms of oxidatively generated DNA modifications, reactivity of products and biological consequences can be found elsewhere [85-87].

DNA damage induced by PDT can result in genotoxicity and mutagenicity [88]. Compared with the impairment on DNA induced by other anticancer treatment regimens, however, the extent of nucleic acid damage is considered to be much smaller [89] and there are no reports that PDT causes secondary tumors [90].

\section{Photosensitizers}

The majority of PSs currently in use for PDT are cyclic tetrapyrrolic structures: porphyrins and their analogs, chlorins, bacteriochlorins, phthalocyanines, etc. (fig. 4). Their advantages and disadvantages have been reviewed in detail [91]. The first PS clinically approved for PDT treatment was a porphyrin named 'hematoporphyrin derivative' (fig. 5a). Its commercial form, Photofrin ${ }^{\circledR}$, is widely used in clinical PDT [92]. Serious shortcomings of this first PS (reviewed by Nyman and Hynninen [93]) stimulated intensive research into the development of compounds which can fulfill as many as possible of the formulated requirements for a good PS [94]. Significant success has been achieved in several aspects: (1) synthesis of stable PSs absorbing light in the red and NIR region of the spectrum $(650-800 \mathrm{~nm})$, which penetrates deeper 


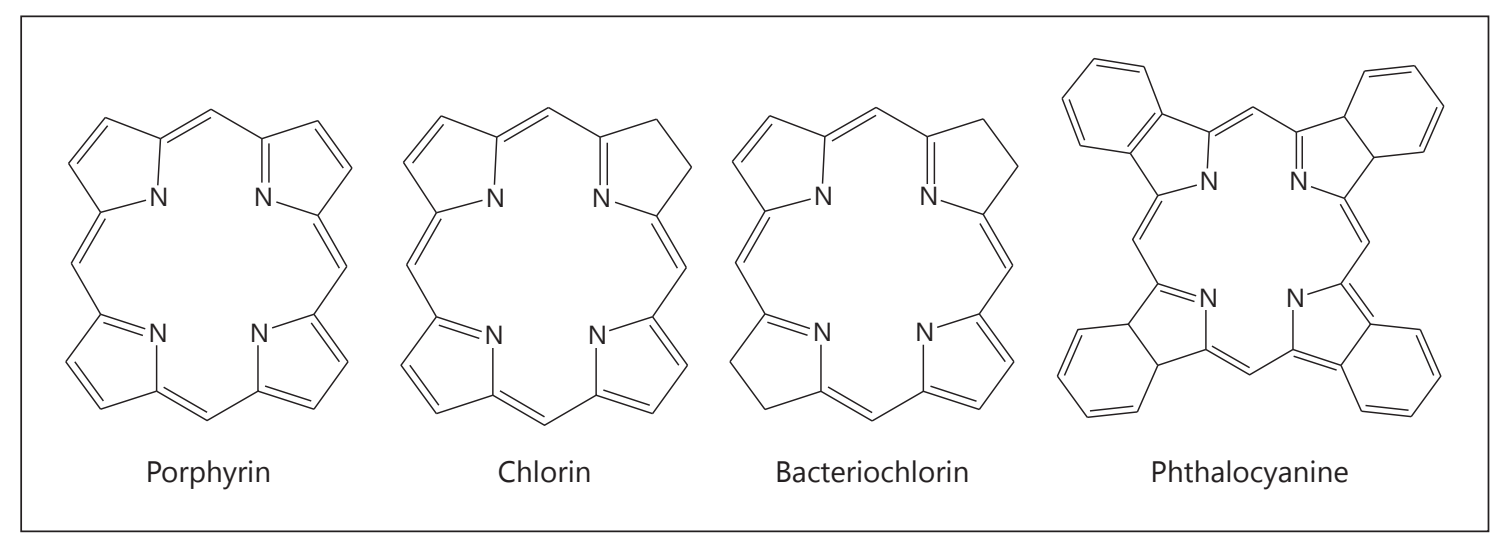

Fig. 4. Main groups of PSs used in PDT.



Fig. 5. Structures of anionic and cationic PSs. a Hematoporphyrin derivative (monomer). b $\mathrm{Zn}$ (II) mesotetrakis(4-carboxyphenyl)porphyrin $\left(\mathrm{ZnTBAP}^{4-}\right)$. c $\mathrm{Zn}(\mathrm{II})$ meso-tetrakis( $N$-methylpyridinium-4-yl)porphyrin $\left(\mathrm{ZnTM}-4-\mathrm{PyP}^{4+}\right)$.

into the tissues $[52,95,96],(2)$ improvement of the selectivity (increasing the target/healthy tissue ratio) and (3) accelerating elimination from the body in order to reduce side effects [97-100]. Increased understanding of the mechanisms of the photodynamic action at cellular and molecular levels helped in formulating strategies for further improvement of PSs. Priority was given to the targeting of the PS to particular cellular organelles, increasing PS uptake by targeted cells and tissues, shifting absorbance of light to longer wavelengths, and accelerating PS clearance from the organism.

Illumination is a key element in PDT and optical properties of tissues determine the depth and efficacy of the treatment. Light scattering and light absorption by endog- enous chromophores (hemoglobin, melanin, etc.) limit light penetration at wavelengths $(\lambda)<650 \mathrm{~nm}$. At $\lambda>1,300$ $\mathrm{nm}$, light penetration in tissues is reduced due to absorption by water molecules. Therefore, maximal penetration of light into tissues can be achieved at the so-called 'phototherapeutic window' [101, 102], which is schematically illustrated in figure 6. Among the natural pigments with strong absorption in the NIR region of the spectrum (720 $850 \mathrm{~nm}$ ) are bacteriochlorins and bacteriopurpurins [103], but they are unstable, easily photobleach, and permit limited chemical modifications [54, 104]. Recently developed new synthetic strategies allowed the synthesis of artificial stable bacteriochlorins, which demonstrated improved pharmacokinetics and high PDT efficacy $[52,54$, 


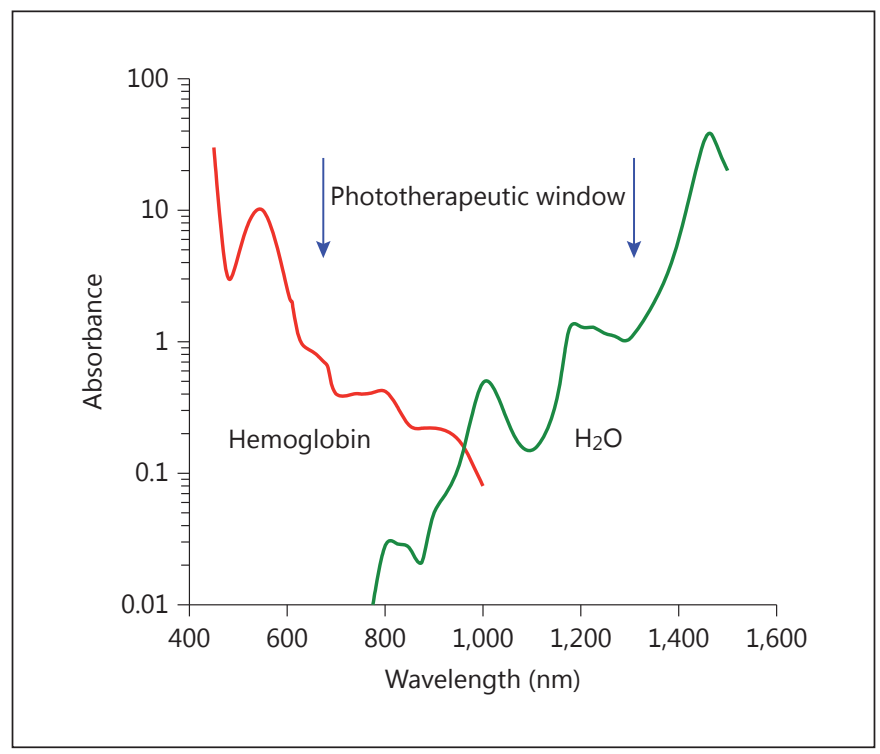

Fig. 6. The optical (phototherapeutic) window, where the absorption and scattering of light by tissues is minimal. For simplicity, only absorption by hemoglobin and water is presented in the logarithmic scale [modified from 102].

$95,96,105]$. Light with $\lambda>850 \mathrm{~nm}$, however, does not provide enough energy for excitation of ${ }^{3} \mathrm{O}_{2}$ to ${ }^{1} \mathrm{O}_{2}[100,106]$. This drawback is eliminated by simultaneous absorption of two photons by the PS, to provide the same energy as a single photon of shorter wavelength [107].

\section{Uptake of PSs}

Due to the limited lifespan and, as a consequence, limited migration distance of ${ }^{1} \mathrm{O}_{2}$ and other photo-generated reactive species in the biological environment, localization of the PS molecule is the main factor determining which structures will be preferentially damaged in PDT. The nature of such targets and the extent of photodamage have a major impact on the physiological reactions and, ultimately, on the PDT outcome.

Three properties of the PS molecule - charge, lipophilicity and three-dimensional structure - are the main determinants of PS uptake and subcellular distribution.

\section{Charge}

Investigations on the effect of electrical charges on PS uptake have revealed that negative charges are unfavorable for PS transport across membranes. However, diffusion across the plasma membrane is possible if a PS pos-

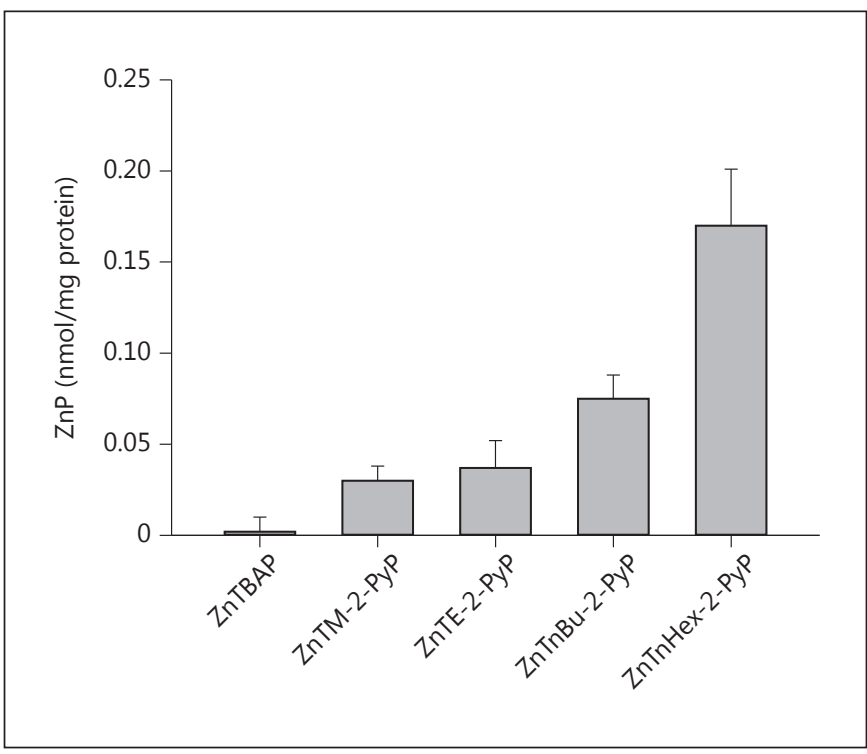

Fig. 7. Uptake of isomeric $\mathrm{ZnPs}$ by human colon adenocarcinoma cells (LS174T). After $24 \mathrm{~h}$ of incubation with $20 \mu \mathrm{M} \mathrm{ZnPs}$ the cells were washed and lysed. PSs were determined in cell-free extracts by estimating the area under the florescence emission peaks. Mean \pm SE is presented $(\mathrm{n}=3)$. $\mathrm{ZnTBAP}=\mathrm{Zn}(\mathrm{II})$ meso-tetrakis (4-carboxyphenyl)porphyrin; ZnTM-2-PyP = Zn(II) meso-tetrakis(N-methylpyridinium-2-yl)porphyrin; ZnTE-2-PyP = Zn(II) meso-tetrakis(N-ethylpyridinium-2-yl)porphyrin; ZnTnBu-2$\mathrm{PyP}=\mathrm{Zn}(\mathrm{II})$ meso-tetrakis(N-butylpyiridinium-2-yl)porphyrin; ZnTnHex-2-PyP = Zn(II) meso-tetrakis $(N$-hexylpyiridinium2-yl)porphyrin.

sesses up to two negative charges, provided their unfavorable effect is compensated with sufficient lipophilicity [102]. More than two negative charges cannot be compensated, which prevents free diffusion of the PS across the plasma membrane $[102,108]$. Such PSs are taken up by endocytosis and accumulate mainly in lysosomes [108]. In contrast, positively charged PSs are efficiently taken up by cells and accumulate intracellularly to concentrations higher than in the environment. The two PSs shown in figure 5, $\mathrm{Zn}$ (II) meso-tetrakis(4-carboxyphenyl)porphyrin (ZnTBAP ${ }^{4-}$ ) (fig. 5b) and $\mathrm{Zn}(\mathrm{II})$ mesotetrakis( $N$-methylpyridinium-4-yl)porphyrin (ZnTM-4$\mathrm{PyP}^{4+}$ ) (fig. 5c) have very similar structures but differ mainly by the net electric charge. The uptake of the cationic Zn-porphyrin, however, is much more effective (fig. 7), which is the reason behind its higher PDT efficacy. Charge differences can explain the inferior PDT activity of the anionic hematoporphyrin derivative (fig. 5a) compared to the cationic $\mathrm{Zn}$ (II) $\mathrm{N}$-alkylpyridylporphyrins [109]. Positively charged PSs are electrostatically at- 




Fig. 8. Structures of cationic $\mathrm{Zn}$ (II) $N$-alkylpyridylporphyrins with progressively increasing lipophilicity. For simplicity, only orthoisomers are shown. a $\mathrm{Zn}$ (II) meso-tetrakis( $N$-methylpyridinium2-yl)porphyrin (ZnTM-2-PyP ${ }^{4+}$ ). b Zn(II) meso-tetrakis( $N$-ethyl- pyridinium-2-yl)porphyrin (ZnTE-2-PyP $\left.{ }^{4+}\right)$. c $\mathrm{Zn}(\mathrm{II})$ mesotetrakis $\left(N\right.$ - butylpyiridinium-2-yl)porphyrin $\left(\mathrm{ZnTnBu}-2-\mathrm{PyP}^{4+}\right)$. d $\mathrm{Zn}$ (II) meso-tetrakis( $N$-hexylpyiridinium-2-yl)porphyrin $\left(\right.$ ZnTnHex-2-PyP $\left.{ }^{4+}\right)$.

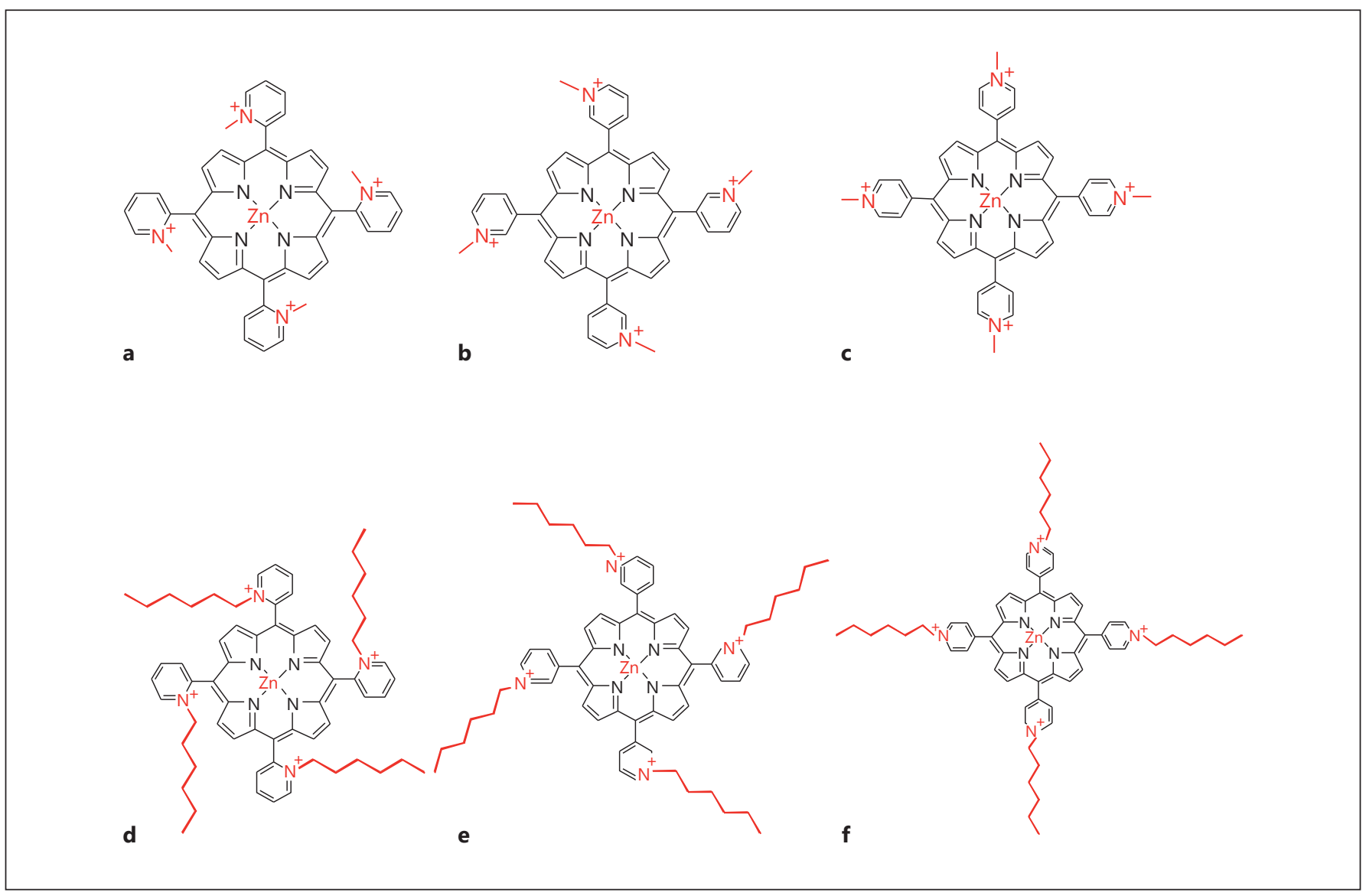

Fig. 9. Isomers of the hydrophilic methyl and the amphiphilic hexyl Zn-porphyrin derivatives. a Ortho, $\mathrm{Zn}(\mathrm{II})$ meso-tetrakis $\left(N\right.$-methylpyridinium-2-yl)porphyrin $\left(\mathrm{ZnTM}-2-\mathrm{PyP}^{4+}\right)$. b Meta, $\mathrm{Zn}(\mathrm{II})$ meso-tetrakis(N-methylpyridinium-3-yl)porphyrin $\left(\mathrm{ZnTM}-3-\mathrm{PyP}^{4+}\right)$. c Para, $\mathrm{Zn}(\mathrm{II})$ meso-tetrakis(N-methylpyri- dinium-4-yl)porphyrin (ZnTM-4-PyP $\left.{ }^{4+}\right)$. d Ortho, Zn(II) mesotetrakis( $N$-hexylpyiridinium-2-yl)porphyrin $\left(\mathrm{ZnTnHex}-2-\mathrm{PyP}^{4+}\right)$. e Meta, $\mathrm{Zn}(\mathrm{II})$ meso-tetrakis( $N$-hexylpyiridinium-3-yl)porphyrin $\left(\mathrm{ZnTnHex}-3-\mathrm{PyP}^{4+}\right)$. f Para, $\mathrm{Zn}(\mathrm{II})$ meso tetrakis( $N$-hexylpyiridinium-3-yl)porphyrin (ZnTnHex-4-PyP $\left.{ }^{4+}\right)$. 
tracted by the predominantly negatively charged components of the plasma and mitochondrial membranes. A critical force driving such positively charged molecules inside cells and mitochondria is the transmembrane potential. Cationic PSs bind to anionic regions on proteins, which probably play an important role in their transport and preferential accumulation in tumor tissue [110]. In addition to the total net charge, distribution (position) of charges in the molecule strongly influences the uptake of PSs [110].

\section{Lipophilicity}

Investigations carried out with a series of cationic meso-substituted porphyrins, where the balance between hydrophilicity and lipophilicity was varied through an increase in the length of the alkyl chains (fig. 8), showed that the uptake of the PS by cancer cells is strongly influenced by the length of the side chain (fig. 7) [111]. Initially, the positively charged porphyrin is attracted electrostatically, but at the vicinity of the membrane lipid bilayer, hydrophobic forces start to dominate. Uptake increases by increasing the length of the alkyl chain from 1 to 8 carbons [112]. It parallels photodynamic efficacy, which also increases as the polarity decreases, reaching a maximum for amphiphilic porphyrins. An increase in the length of the alkyl chains above certain limits leads to suppression of cellular uptake [99]. It has been proposed that the length of the aliphatic chain affects the binding of molecules to cellular membranes. A chain with optimal length eventually favors the insertion of the PS deeper into the lipid bilayer of biological membranes [99].

Lipophilicity affects not only the uptake of the PSs, but also their subcellular distribution. For cationic metalloporphyrins, an increase in the length of the aliphatic tail from 2 to 6 carbons shifts subcellular localization of the molecules from cytosolic to mitochondrial [111].

\section{Shape, Size and Three-Dimensional Structure of the Molecule}

In contrast to the contribution of charges and lipophilicity, much less is known about the effect of shape and size of the PS molecule on cellular uptake, subcellular distribution and PDT activity. In a study investigating how lipophilicity of asymmetric porphyrins affects their incorporation in membranes, Engelmann et al. [113] found that lipophilicity alone was not a sufficient predictor of membrane binding. The spatial structure of the molecule is a factor which determines the depth a PS would penetrate into the lipid bilayer of membranes, and the strength of hydrophobic and hydrophilic interactions. It has been

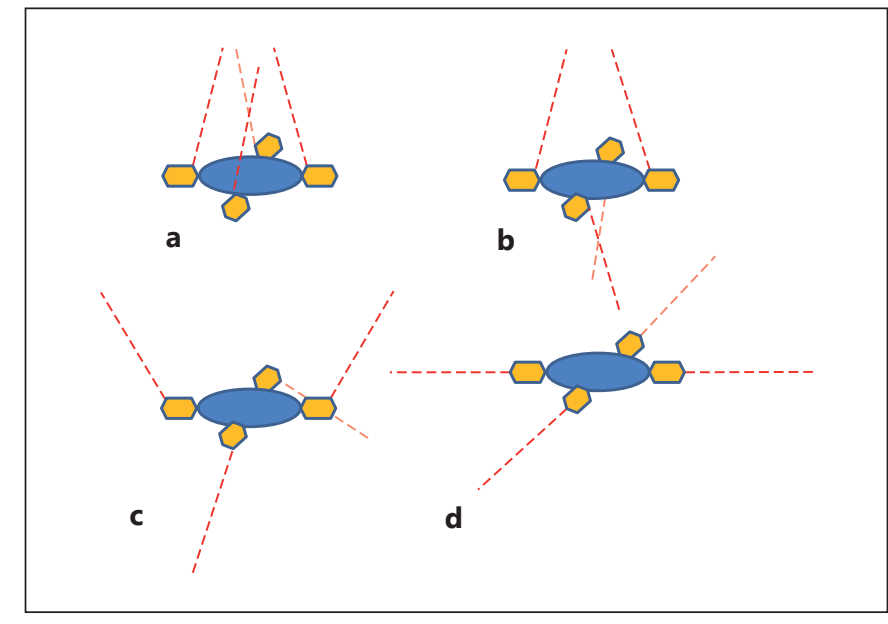

Fig. 10. Schematic representation of the three-dimensional shapes of the ortho-, meta- and para-hexyl isomers. The porphyrin core is represented by a blue ellipse, pyridyl substituents at meso-position by yellow hexagons and aliphatic chains by dotted red lines. For simplicity, only $\alpha a \alpha \alpha$ and $\alpha \beta \alpha \beta$ atropisomers of ortho-isomer are presented. a ZnTnHex-2-PyP aaaa. b ZnTnHex-2-PyP $\alpha \beta \alpha \beta$. c ZnTnHex-3-PyP. d ZnTnHex-4-PyP [modified from 111].

concluded that PDT efficacy depends not only on the amount of bound PS but also on its location [113].

Studies on structurally related cationic metalloporphyrins revealed that, together with charge and lipophilicity, shape and bulkiness play an important role in cellular uptake and subcellular distribution of the molecules (for detailed review see Tovmasyan et al. [114]). The ortho-isomer ZnTM-2-PyP ${ }^{4+}$ (fig. 9a), of the hydrophilic methyl analog, displays cytoplasmic distribution with preferential lysosomal uptake. The meta-methyl isomer $\mathrm{ZnTM}-3-\mathrm{PyP}^{4+}$ (fig. 9b) is found in both the nucleus and the cytoplasm, and accumulation of its para-analog (fig. 9c) is predominantly nuclear. Thus, moving the substituents from ortho- to para-position shifts the localization of the hydrophilic PS from cytoplasmic to nuclear [111]. For the amphiphilic hexyl derivatives, however, moving the hexyl alkyl chain from ortho- to para-position (fig. 9d-f) does not lead to the translocation of the PS to the nucleus. In contrast, such change in the spatial structure of the molecule affects its incorporation in the lipid bilayer of the membranes [111]. The reasons for such differences among the structural isomers of the same compound can be understood if the three-dimensional shape of the molecules is taken into consideration. Each structural ortho-isomer can have up to 4 atropoisomers, each determining a particular three-dimension- 
al shape. The effect of the position of the alkyl chain on the shape and size of the molecule is schematically illustrated in figure 10. The aada atropo-isomer of the orthoanalog is more compact, with charges allocated on one side and aliphatic tails facing the opposite side of the molecule (fig. 10a). The $\alpha \beta \alpha \beta$ atropo-isomer is more symmetrical, with positive charges in the middle and lipophilic tails at both sides of the molecule (fig. 10b). Such conformation hides the positive charges and obstructs electrostatic interactions with neighboring molecules. In the meta-analog (fig. 10c), the aliphatic chains are more extended, and charges can be less accessible than in the corresponding ortho-isomer. The para-analog (fig. 10d), in contrast, is more planar and more flexible, with positive charges encircled by the aliphatic tails [111]. Such differences in size, shape, charge accessibility and orientation of the lipophilic chains determine the strength of electrostatic and hydrophobic interactions of the PS with neighboring molecules, which directs the translocation and the distribution of the PS to cellular structures and organelles.

\section{Relationship between Subcellular Distribution of PSs and PDT Efficacy}

Cellular compartments vary substantially by sensitivity toward photo-generated reactive species. As a consequence, the subcellular distribution of PSs is a strong predictor of their PDT efficacy. The localization of photodamage to specific subcellular targets is critical for the activation of particular signaling/regulatory pathways and the magnitude and type of cellular response, as well as for the mode of cell death following PDT [115].

\section{Lysosomes}

Initially, lysosomes were considered the main intracellular PDT target, and it was believed that disruption of lysosomes was the main reason behind cell killing. It has been proposed that as a result of photo-induced disruption of lysosomal membranes, the cell is digested by released hydrolytic enzymes. Further studies demonstrated, however, that although PSs localized in lysosomes can lead to cell killing upon illumination, the relative efficacy of lysosome-localized PSs is significantly lower than that seen with PSs localized in mitochondria and other organelles. A possible reason is inactivation of lysosomal enzymes by the PDT treatment and/or inhibition by cytosolic inhibitors [116].

\section{Mitochondria}

PSs that localize to mitochondria are reported to be more efficient in killing cells than those that localize at other cellular sites. Mitochondria are among the first organelles to show ultrastructural changes after photosensitization. Mitochondrial targeting is considered particularly important for effective anticancer therapy because inhibition of mitochondrial functions and/or damage to mitochondrial components is very critical for cell survival and may induce rapid apoptotic response [99]. Photodynamic damage to mitochondria is a primary event in a chain of processes that result in disruption of the electron transport chain, dissipation of the mitochondrial membrane potential and mitochondrial swelling.

\section{Biomembranes}

Photodynamic efficacy is directly proportional to membrane binding of PSs, indicating that favorable membrane interactions are a key factor for achieving high PDT efficacy [112]. If a PS is anchored within a membrane, the excited triplet species formed after illumination would encounter an elevated concentration of oxygen and more singlet oxygen would be generated. In addition, ${ }^{1} \mathrm{O}_{2}$ produced within the membrane has higher chances to react with sensitive membrane components, including polyunsaturated fatty acids. In contrast, if the PS remains at the membrane boundary or in the water environment, it will interact with lower aqueous oxygen concentrations and a larger fraction of the generated singlet oxygen will be deactivated before encountering and oxidizing sensitive cellular components [117]. The complexity of biomembranes and their crucial role for cell survival can explain the high PDT activity of membrane-localized PSs. Even mild PDTinduced membrane oxidation can result in loss of membrane barrier function [70], inactivation of membranebound protein complexes [61], modifications of cell receptors and interruption of cell signaling cascades [118] (or alterations in any other essential membrane functions), which ultimately can lead to cell death.

\section{Cytoskeleton}

Cytoskeletal elements are another attractive target for PDT. PSs with a high affinity for binding to nonpolymerized tubulin can be highly cytotoxic. By specifically binding to tubulin and after illumination, preventing its polymerization, low doses of PSs can act in a manner similar to inhibitors of microtubule function $[119,120]$. Photodynamic action targeted at tubulin induces the formation of micronuclei and giant cells and the accumulation of cells in mitosis [116]. 


\section{The Mode of Cell Death}

Various factors govern the type of cell death by PDT (reviewed in detail by Mroz et al. [121]). Among the most important are physicochemical properties of PS, its subcellular localization and local concentration, the concentration of oxygen, and the wavelength and intensity of light used for illumination [88, 122]. All other conditions being equal, PSs that localize to mitochondria induce apoptotic cell death within a certain threshold of oxidative stress. Particularly with mitochondria, apoptotic cell death can ensue not only from oxidative damage induced by primary, photo-degenerated ROS, but also by superoxide anion generated as a secondary product due to photodamage of components of the electron transport chain [123]. In contrast, PSs targeting lysosomes either delay or block the apoptotic program, thus predisposing the cells to necrosis. Mild oxidative damage by PSs localized in the plasma membrane cause apoptosis, but extensive damage leading to loss of plasma membrane integrity brings necrotic cell death $[115,124,125]$. Photosynthesizers targeting the endoplasmic reticulum/Golgi membranes have been reported to mediate necrosis. In summary, the type of death following PDT depends on the quantity, the site and the type of ROS generated by the photodynamic process, which in turn determine the extent of the oxidative damage [126]. The same PS can cause necrosis if illumination is done under normoxic conditions, but induces apoptotic death if illumination is carried out under hypoxic conditions [84]. It has been proposed that photoinactivation of essential enzymes and other components of the apoptotic cascade is the main reason for necrotic death under conditions of high PDT intensity [88]. Sublethal damage signals the cell to die by apoptosis, while severe damage prevents ATP production and execution of the apoptotic pathways and forces the cell to die by necrosis $[122,127]$.

Results from recent studies suggest that the type of photo-induced cell death has a strong impact on the clinical outcome of PDT. PDT with very low light fluence rates, which is known to cause predominantly apoptotic cell death [128-130], minimizes side effects, improves tumor control and reduces treatment-related morbidity without hampering therapeutic efficacy [131-133].

\section{Adverse Reactions and Current Limitations of PDT}

Compared to surgery or radiation therapy, PDT is less invasive and adverse reactions are relatively mild and not long-lasting. Depending on the PS and the therapeutic protocol, adverse events associated with PDT include photosensitivity, erythema, edema, fever, pleural effusion, constipation, anemia and respiratory insufficiency [134]. The principal side effect of PDT is pain, which usually occurs in the early part of irradiation and then gradually decreases over time [134-136]. The mechanism of PDT-induced pain is not well understood, but in most cases it can be well controlled by a combination of opiate, opioid and nonsteroidal anti-inflammatory drugs [137]. Photosensitivity is another common complication, which can last for months. In the majority of cases it is mild-tomoderate and requires no treatment. Photophobia, visual discomfort and dyschromias are also listed among the side effects of PDT [134]. It is important to stress that most side effects can be alleviated by the proper selection of the type of PS and PS dosage, parameters of illumination and other details of the PDT treatment protocol. Standardization of the treatment protocols and prediction of the PDT response, however, are seriously hampered by the lack of established PDT dosimetry [138]. In contrast to ionizing radiation, no agreement has been reached on how the doses of PS and light should be measured, and even no widely accepted definition of dose exists. In addition, the optimum PS and light doses as well as drug-light time interval may vary from patient to patient or lesion to lesion, which prevents the application of standardized protocols and the achievement of highest response rates.

Among the limitations of PSs currently used for clinical PDT are the difficulty in treating large tumor masses and the limited depth of treatment. Visible light can penetrate the tissues not deeper than 5-10 $\mathrm{mm}$, which restricts the application of PDT to mainly superficial lesions. A detailed description of the current state of PDT and its limitations can be found in comprehensive reviews $[134,138]$.

\section{Strategies for Perfecting PDT}

The development of better, more efficient compounds, free of the shortcomings of the first- and second-generation PSs, is among the primary strategies for improving PDT. This includes synthesis of PSs with strong absorption bands in the NIR region of the spectrum [139], which overcomes one of the main limitations of the currently clinically approved PSs - the insufficient depth of treatment. Improvement of PSs can be aided by the latest advances in nanotechnology. Nanoparticles have been used as PSs themselves, for delivery of PSs or as energy trans- 
ducers [100]. Targeted delivery of PSs is achieved by conjugation with antibodies, engineered synthesis of molecules with specific structure and even by attachment of PSs to magnetic nanoparticles. In the latter case, an externally applied magnetic field directs the PS to the lesion [100]. Attachment of different modules to PSs, for example DNA- or peptide-based linkers and cancer cell-specific delivery vehicles, is used to improve both target specificity and pharmacological properties [140]. In addition to the efforts in developing better PSs, various strategies driven by the current understanding of photophysics, photochemistry, photobiology and the latest technological advances have been evolved to meet the requirements for effective PDT outcome. Deep treatment, using PSs absorbing in the NIR region of the spectrum, is achieved by two-photon PDT [141]. It is based on the development of laser technology, which allows the application of short (approx. $100 \mathrm{fs}$ ) laser pulses with high peak power. Instead of one, two light photons are absorbed and each photon accounts for only half of the excitation energy [142]. Metronomic PDT is based on the application of very low doses of PSs combined with low rates of irradiation lasting for extended periods of time [143]. As mentioned before, the outcome is cell death by apoptosis with minimal tissue necrosis.

Irrespective of the advances in laser technology, synthetic chemistry, nanotechnology and photobiology,
PDT, more than a quarter of a century after its first clinical approval, is still not accepted as 'standard' therapy even in areas of medicine where real improvement in outcome using standard therapy has not been achieved [144]. The solution of this problem has been summarized by Moghissi [144], who recommends that, in order to overcome the current challenges and rise to the height of its potential, PDT needs commitment and funds [144].

\section{Acknowledgments}

This review is based on results obtained in collaboration with I. Batinic-Haberle and A. Tovmasyan (Duke University Medical Center, USA), J. Rebucas (Universidade Federal da Paraíba, Brazil) and J. Craik and A. Al-Banaw (Kuwait University), and on data derived from MSc theses of D. Al-Mutairi, M. Ghazal, R. Ezzeddine and A. Odeh. Financial support was received from Kuwait University (research grants MB02/12, YM02/08, YM03/11, YM05/11 and SRUL02/13) and the College of Graduate Studies. The author is grateful to Prof. C. Ford and Prof. M. Alkhalaf for providing cancer cell lines and to M. Thomas, E. Jayanthy, F. Sequeira and the staff of HSC Omics for their excellent technical assistance.

\section{Disclosure Statement}

The author has no conflict of interest.

\section{References}

1 Dougherty TJ, Gomer CJ, Henderson BW, et al: Photodynamic therapy. J Natl Cancer Inst 1998;90:889-905.

2 Waksman R, McEwan PE, Moore TI, et al: PhotoPoint photodynamic therapy promotes stabilization of atherosclerotic plaques and inhibits plaque progression. J Am Coll Cardiol 2008;52:1024-1032.

3 Woodburn KW, Fan Q, Kessel D, et al: Phototherapy of cancer and atheromatous plaque with texaphyrins. J Clin Laser Med Surg 1996; 14:343-348.

4 Bozzini G, Colin P, Betrouni N, et al: Photodynamic therapy in urology: what can we do now and where are we heading? Photodiagnosis Photodyn Ther 2012;9:261-273.

5 Cotter TG: Apoptosis and cancer: the genesis of a research field. Nat Rev Cancer 2009;9: 501-507.

-6 Silva JN, Filipe P, Morliere P, et al: Photodynamic therapy: dermatology and ophthalmology as main fields of current applications in clinic. Biomed Mater Eng 2008;18:319-327.

Photodynamic Therapy
Michels S, Schmidt-Erfurth U: Photodynamic therapy with verteporfin: a new treatment in ophthalmology. Semin Ophthalmol 2001;16: 201-206.

8 Meisel P, Kocher T: Photodynamic therapy for periodontal diseases: state of the art. J Photochem Photobiol B 2005;79:159-170.

-9 Konopka K, Goslinski T: Photodynamic therapy in dentistry. J Dental Res 2007;86:694707.

10 Babilas P, Schreml S, Landthaler M, et al: Photodynamic therapy in dermatology: state-ofthe-art. Photodermatol Photoimmunol Photomed 2010;26:118-132.

11 Lee Y, Baron ED: Photodynamic therapy: current evidence and applications in dermatology. Semin Cutan Med Surg 2011;30:199-209.

12 Szeimies RM, Lischner S, Philipp-Dormston $\mathrm{W}$, et al: Photodynamic therapy for skin rejuvenation: treatment options - results of a consensus conference of an expert group for aesthetic photodynamic therapy. J Dtsch Dermatol Ges 2013;11:632-636.
13 Taub AF: Cosmetic clinical indications for photodynamic therapy. J Cosmet Dermatol 2012;25:218-224.

14 Costa L, Faustino MAF, Neves MGPMS, et al: Photodynamic inactivation of mammalian viruses and bacteriophages. Viruses 2012;4: 1034-1074.

15 Wainwright M: Local treatment of viral disease using photodynamic therapy. Int J Antimicrob Agents 2003;21:510-520.

16 Arenas Y, Monro S, Shi G, et al: Photodynamic inactivation of Staphylococcus aureus and methicillin-resistant $S$. aureus with $\mathrm{Ru}(\mathrm{II})$ based type I/type II photosensitizers. Photodiagnosis Photodyn Ther 2013;10:615-625.

17 Sperandio FF, Huang YY, Hamblin MR: Antimicrobial photodynamic therapy to kill Gram-negative bacteria. Recent Pat Antiinfect Drug Discov 2013;8:108-120.

18 Calzavara-Pinton P, Rossi MT, Sala R, et al: Photodynamic antifungal chemotherapy. Photochem Photobiol 2012;88:512-522. 
19 Paz-Cristobal MP, Royo D, Rezusta A, et al: Photodynamic fungicidal efficacy of hypericin and dimethyl methylene blue against azole-resistant Candida albicans strains. Mycoses 2014;57:35-42.

20 Pereira Gonzales F, Maisch T: Photodynamic inactivation for controlling Candida albicans infections. Fungal Biol 2012;116:1-10.

21 Wainwright M: Pathogen inactivation in blood products. Curr Med Chem 2002;9:127143.

22 Bonnett R, Krysteva MA, Lalov IG, et al: Water disinfection using photosensitizers immobilized on chitosan. Water Res 2006;40:12691275.

23 Magaraggia M, Faccenda F, Gandolfi A, et al: Treatment of microbiologically polluted aquaculture waters by a novel photochemical technique of potentially low environmental impact. J Environ Monit 2006;8:923-931.

24 Brovko L: Photodynamic treatment. A new efficient alternative for surface sanitation. Adv Food Nutr Res 2010;61:119-147.

-25 Maisch T, Spannberger F, Regensburger J, et al: Fast and effective: intense pulse light photodynamic inactivation of bacteria. J Ind Microbiol Biotechnol 2012;39:1013-1021.

26 Berg K, Folini M, Prasmickaite L, et al: Photochemical internalization: a new tool for drug delivery. Curr Pharm Biotechnol 2007;8:362372.

27 Berg K, Høgset A, Prasmickaite L, et al: Photochemical internalization (PCI): a novel technology for activation of endocytosed therapeutic agents. Med Laser Appl 2006;21: 239-250.

28 Ogilby PR: Singlet oxygen: there is indeed something new under the sun. Chem Soc Rev 2010;39:3181-3209.

29 Mroz P, Bhaumik J, Dogutan DK, et al: Imidazole metalloporphyrins as photosensitizers for photodynamic therapy: role of molecular charge, central metal and hydroxyl radical production. Cancer Lett 2009;282:63-76.

30 Fridovich I: Oxygen toxicity: a radical explanation. J Exp Biol 1998;201:1203-1209.

- 31 Fee JA: Is superoxide important in oxygen poisoning? Trends Biochem Sci 1982;7:8486.

-32 Winterbourn CC, Kettle AJ: Radical-radical reactions of superoxide: a potential route to toxicity. Biochem Biophys Res Commun 2003;305:729-736.

- 33 d'Alessandro N, Bianchi G, Fang X, et al: Reaction of superoxide with phenoxyl-type radicals. J Chem Soc Perkin Trans II 2000;18621867.

-34 Nagy P, Kettle AJ, Winterbourn CC: Superoxide-mediated formation of tyrosine hydroperoxides and methionine sulfoxide in peptides through radical addition and intramolecular oxygen transfer. J Biol Chem 2009;284 14723-14733.
Misiaszek R, Crean C, Joffe A, et al: Oxidative DNA damage associated with combination of guanine and superoxide radicals and repair mechanisms via radical trapping. J Biol Chem 2004;279:32106-32115.

36 Huie RE, Padmaja S: The reaction of NO with superoxide. Free Radic Res Commun 1993; 18:195-199.

37 Beckman JS, Beckman TW, Chen J, et al: Apparent hydroxyl radical production by peroxynitrite - implications for endothelial injury from nitric-oxide and superoxide. Proc Natl Acad Sci USA 1990;87:1620-1624.

38 Lymar SV, Hurst JK: Rapid reaction between peroxonitrite ion and carbon dioxide: implications for biological activity. J Am Chem Soc 1995; $117: 8867-8868$

39 Medinas DB, Cerchiaro G, Trindade DF, et al: The carbonate radical and related oxidants derived from bicarbonate buffer. IUBMB Life 2007:59:255-262.

40 Shafirovich V, Dourandin A, Huang WD, et al: The carbonate radical is a site-selective oxidizing agent of guanine in double-stranded oligonucleotides. J Biol Chem 2001;276: 24621-24626

41 Benov L: How superoxide radical damages the cell. Protoplasma 2001;217:33-36.

42 Liochev SI, Fridovich I: The role of O2 - - in the production of $\mathrm{HO} \cdot$ : in vitro and in vivo. Free Radic Biol Med 1994;16:29-33.

43 Liochev SI: The role of iron-sulfur clusters in in vivo hydroxyl radical production. Free Radic Res 1996;25:369-384.

44 Imlay JA: The molecular mechanisms and physiological consequences of oxidative stress: lessons from a model bacterium. Nat Rev Microbiol 2013;11:443-454.

45 Fridovich I: Oxygen: how do we stand it? Med Princ Pract 2013;22:131-137.

46 Davies MJ: Reactive species formed on proteins exposed to singlet oxygen. Photochem Photobiol Sci 2004;3:17-25.

-47 DeRosa MC, Crutchley RJ: Photosensitized singlet oxygen and its applications. Coord Chem Rev 2002;233-234:351-371.

48 Rodgers MA, Snowden PT: Lifetime of $\mathrm{O}_{2}$ $\left({ }^{1} \Delta_{\mathrm{g}}\right)$ in liquid water as determined by timeresolved infrared luminescence measurements. J Am Chem Soc 1982;104:5541-5543.

49 Redmond RW, Kochevar IE: Spatially resolved cellular responses to singlet oxygen. Photochem Photobiol 2006;82:1178-1186.

50 Ashur I, Goldschmidt R, Pinkas I, et al: Photocatalytic generation of oxygen radicals by the water-soluble bacteriochlorophyll derivative WST11, noncovalently bound to serum albumin. J Phys Chem A 2009;113:8027-8037.

51 Pattison DI, Rahmanto AS, Davies MJ: Photooxidation of proteins. Photochem Photobiol Sci 2012;11:38-53.

52 Dabrowski JM, Arnaut LG, Pereira MM, et al: New halogenated water-soluble chlorin and bacteriochlorin as photostable PDT sensitizers: synthesis, spectroscopy, photophysics, and in vitro photosensitizing efficacy. Chem Med Chem 2010;5:1770-1780.
53 Dabrowski JM, Arnaut LG, Pereira MM, et al: Combined effects of singlet oxygen and hydroxyl radical in photodynamic therapy with photostable bacteriochlorins: evidence from intracellular fluorescence and increased photodynamic efficacy in vitro. Free Radic Bio Med 2012;52:1188-1200.

-54 Huang YY, Balasubramanian T, Yang E, et al Stable synthetic bacteriochlorins for photodynamic therapy: role of dicyano peripheral groups, central metal substitution $(2 \mathrm{H}, \mathrm{Zn}$, $\mathrm{Pd})$, and Cremophor EL delivery. Chem Med Chem 2012;7:2155-2167.

55 Plowman JE, Deb-Choudhury S, Grosvenor AJ, et al: Protein oxidation: identification and utilisation of molecular markers to differentiate singlet oxygen and hydroxyl radical-mediated oxidative pathways. Photochem Photobiol Sci 2013;12:1960-1967.

56 Davies MJ: The oxidative environment and protein damage. Biochim Biophys Acta 2005; 1703:93-109.

57 Garrison WM: Reaction mechanisms in the radiolysis of peptides, polypeptides, and proteins. Chem Rev 1987;87:381-398.

58 Winterbourn CC, Parsons-Mair HN, Gebicki $S$, et al: Requirements for superoxide-dependent tyrosine hydroperoxide formation in peptides. Biochem J 2004;381:241-248.

59 Das AB, Nagy P, Abbott HF, et al: Reactions of superoxide with the myoglobin tyrosyl radical. Free Radic Biol Med 2010;48:1540-1547.

60 Alvarez B, Radi R: Peroxynitrite reactivity with amino acids and proteins. Amino Acids 2003;25:295-311.

61 Benov L, Craik J, Batinic-Haberle I: Protein damage by photo-activated $\mathrm{Zn}$ (II) N-alkylpyridylporphyrins. Amino Acids 2012;42: 117-128.

-62 Afonso SC, Enríquez De Salamanca R, Del C. Batlle AM: The photodynamic and non-photodynamic actions of porphyrins. Brazil J Med Biol Res 1999;32:255-266.

63 Al-Mutairi DA, Craik JD, Batinic-Haberle I, et al: Inactivation of metabolic enzymes by photo-treatment with zinc meta-N-methylpyridylporphyrin. Biochim Biophys Acta 2007;1770:1520-1527.

64 Girotti AW: Photosensitized oxidation of membrane lipids: reaction pathways, cytotoxic effects, and cytoprotective mechanisms. J Photochem Photobiol 2001;63:103-113.

-65 Doleiden FH, Fahrenholtz SR, Lamola AA, et al: Reactivity of cholesterol and some fatty acids toward singlet oxygen. Photochem Photobiol 1974;20:519-521.

66 Girotti AW, Kriska T: Role of lipid hydroperoxides in photo-oxidative stress signaling. Antioxid Redox Signal 2004;6:301-310.

67 Yoshida Y, Niki E: Oxidation of methyl linoleate in aqueous dispersions induced by copper and iron. Arch Biochem Biophys 1992; 295:107-114. 
68 Guéraud F, Atalay M, Bresgen N, et al: Chemistry and biochemistry of lipid peroxidation products. Free Radic Res 2010;44:1098-1124.

-69 Epe B: DNA damage spectra induced by photosensitization. Photochem Photobiol Sci 2012;11:98-106.

-70 Al-Mutairi DA, Craik JD, Batinic-Haberle I, et al: Photosensitizing action of isomeric zinc $\mathrm{N}$-methylpyridyl porphyrins in human carcinoma cells. Free Radic Res 2006;40:477-483.

71 Barrera G, Pizzimenti S, Dianzani MU: Lipid peroxidation: control of cell proliferation, cell differentiation and cell death. Mol Aspects Med 2008;29:1-8.

-72 Negre-Salvayre A, Auge N, Ayala V, et al: Pathological aspects of lipid peroxidation. Free Radic Res 2010;44:1125-1171.

73 Niki E: Lipid peroxidation: physiological levels and dual biological effects. Free Radic Biol Med 2009;47:469-484.

74 Uchida K: Lipid peroxidation and redox-sensitive signaling pathways. Curr Atheroscler Rep 2007;9:216-221.

75 Cadet J, Ravanat JL, TavernaPorro M, et al: Oxidatively generated complex DNA damage: tandem and clustered lesions. Cancer Lett 2012;327:5-15.

76 Cadet J, Douki T, Ravanat JL: One-electron oxidation of DNA and inflammation processes. Nat Chem Biol 2006;2:348-349.

-77 Cadet J, Douki T, Ravanat JL: Oxidatively generated damage to the guanine moiety of DNA: mechanistic aspects and formation in cells. Acc Chem Res 2008;41:1075-1083.

78 Cadet J, Mouret S, Ravanat JL, et al: Photoinduced damage to cellular DNA: direct and photosensitized reactions. Photochem Photobiol 2012;88:1048-1065.

-79 Cadet J, Douki T, Ravanat JL: Oxidatively generated base damage to cellular DNA. Free Radic Biol Med 2010;49:9-21.

$\$ 80$ Pouget JP, Douki T, Richard MJ, et al: DNA damage induced in cells by $\gamma$ and UVA radiation as measured by HPLC/GC-MS and HPLC-EC and comet assay. Chem Res Toxicol 2000;13:541-549.

81 Epe B: Genotoxicity of singlet oxygen. Chem Biol Interact 1991;80:239-260.

82 Sies H, Menck CF: Singlet oxygen induced DNA damage. Mutat Res 1992;275:367-375.

83 Cooke MS, Loft S, Olinski R, et al: Recommendations for standardized description of and nomenclature concerning oxidatively damaged nucleobases in DNA. Chem Res Toxicol 2010;23:705-707.

-84 Al-Mutairi DA, Craik JD, Batinic-Haberle I, et al: Induction of oxidative cell damage by photo-treatment with zinc N-methylpyridylporphyrin. Free Radic Res 2007;41:89-96.

85 Cadet J, Loft S, Olinski R, et al: Biologically relevant oxidants and terminology, classification and nomenclature of oxidatively generated damage to nucleobases and 2-deoxyribose in nucleic acids. Free Radic Res 2012;46: 467-481.
86 Cadet J, Wagner JR: DNA base damage by reactive oxygen species, oxidizing agents, and UV radiation. Cold Spring Harb Perspect Biol 2013;5:a012559.

87 Dedon PC: The chemical toxicology of 2-deoxyribose oxidation in DNA. Chem Res Toxicol 2008;21:206-219.

$\checkmark 8$ Castano AP, Demidova TN, Hamblin MR: Mechanisms in photodynamic therapy. Part 2. Cellular signaling, cell metabolism and modes of cell death. Photodiagnosis Photodyn Ther 2005;2:1-23.

89 Moan J, Berg K, Kvam E: Effects of photodynamic treatment on DNA and DNA related cell functions; in Photodynamic Therapy of Neoplastic Disease. Boca Raton, CRC Press, 1990.

90 Fuchs J, Weber S, Kaufmann R: Genotoxic potential of porphyrin type photosensitizers with particular emphasis on 5-aminolevulinic acid: implications for clinical photodynamic therapy. Free Radic Biol Med 2000;28: 537-548.

91 Ormond AB, Freeman HS: Dye sensitizers for photodynamic therapy. Materials 2013; 6:817-840.

-92 Wolfsen HC: Porfimer sodium photodynamic therapy: the long road to acceptance in America. Photodiagnosis Photodyn Ther 2007;4:242-243.

-93 Nyman ES, Hynninen PH: Research advances in the use of tetrapyrrolic photosensitizers for photodynamic therapy. J Photochem Photobiol B 2004;73:1-28.

94 Pushpan SK, Venkatraman S, Anand VG, et al: Porphyrins in photodynamic therapy: a search for ideal photosensitizers. Curr Med Chem Anticancer Agents 2002;2:187-207.

-95 Dabrowski JM, Arnaut LG, Pereira MM, et al: Improved biodistribution, pharmacokinetics and photodynamic efficacy using a new photostable sulfonamide bacteriochlorin. Med Chem Commun 2012;3:502-505.

-96 Yang E, Diers JR, Huang YY, et al: Molecular electronic tuning of photosensitizers to enhance photodynamic therapy: synthetic dicyanobacteriochlorins as a case study. Photochem Photobiol 2013;89:605-618.

$\$ 97$ St Denis TG, Hamblin MR: Synthesis, bioanalysis and biodistribution of photosensitizer conjugates for photodynamic therapy. Bioanalysis 2013;5:1099-1114.

98 Master A, Livingston M, Sen Gupta A: Photodynamic nanomedicine in the treatment of solid tumors: perspectives and challenges. J Control Release 2013;168:88-102.

99 Ricchelli F, Franchi L, Miotto G, et al: Mesosubstituted tetra-cationic porphyrins photosensitize the death of human fibrosarcoma cells via lysosomal targeting. Int J Biochem Cell Biol 2005;37:306-319.

100 Agostinis P, Berg K, Cengel KA, et al: Photodynamic therapy of cancer: an update. CA Cancer J Clin 2011;61:250-281.

101 Yoon I, Li JZ, Shim YK: Advance in photosensitizers and light delivery for photodynamic therapy. Clin Endosc 2013;46:7-23.
102 Castano AP, Demidova TN, Hamblin MR: Mechanisms in photodynamic therapy. Part 1. Photosensitizers, photochemistry and cellular localization. Photodiagnosis Photodyn Ther 2004;1:279-293.

103 Huang YY, Mroz P, Zhiyentayev T, et al: In vitro photodynamic therapy and quantitative structure-activity relationship studies with stable synthetic near-infrared-absorbing bacteriochlorin photosensitizers. J Med Chem 2010;53:4018-4027.

104 Mroz P, Huang YY, Szokalska A, et al: Stable synthetic bacteriochlorins overcome the resistance of melanoma to photodynamic therapy. FASEB J 2010;24:3160-3170.

105 Dabrowski JM, Urbanska K, Arnaut LG, et al: Biodistribution and photodynamic efficacy of a water-soluble, stable, halogenated bacteriochlorin against melanoma. Chem Med Chem 2011;6:465-475.

106 Juzeniene A, Nielsen KP, Moan J: Biophysical aspects of photodynamic therapy. J Environ Pathol Toxicol Oncol 2006;25:7-28.

107 Aggarwal A, Thompson S, Singh S, et al: Photophysics of glycosylated derivatives of a chlorin, isobacteriochlorin and bacteriochlorin for photodynamic theragnostics: discovery of a two-photon-absorbing photosensitizer. Photochem Photobiol 2014;90: 419-430.

108 Boyle RW, Dolphin D: Structure and biodistribution relationships of photodynamic sensitizers. Photochem Photobiol 1996;64: 469-485.

109 Benov L, Batinic-Haberle I, Spasojevic I, et al: Isomeric $\mathrm{N}$-alkylpyridylporphyrins and their $\mathrm{Zn}$ (II) complexes: inactive as SOD mimics but powerful photosensitizers. Arch Biochem Biophys 2002;402:159-165.

110 Jensen TJ, Vicente MGH, Luguya R, et al: Effect of overall charge and charge distribution on cellular uptake, distribution and phototoxicity of cationic porphyrins in HEp2 cells. J Photochem Photobiol B 2010;100:100111.

111 Ezzeddine R, Al-Banaw A, Tovmasyan A, et al: Effect of molecular characteristics on cellular uptake, subcellular localization, and phototoxicity of $\mathrm{Zn}$ (II) N-alkylpyridylporphyrins. J Biol Chem 2013;288:3657936588.

112 Pavani C, Uchoa AF, Oliveira CS, et al: Effect of zinc insertion and hydrophobicity on the membrane interactions and PDT activity of porphyrin photosensitizers. Photochem Photobiol Sci 2009;8:233-240.

113 Engelmann FM, Mayer I, Gabrielli DS, et al: Interaction of cationic meso-porphyrins with liposomes, mitochondria and erythrocytes. J Bioenerg Biomembr 2007;39:175185.

14 Tovmasyan A, Reboucas JS, Benov L: Simple biological systems for assessing the activity of superoxide dismutase mimics. Antioxid Redox Signal DOI: 10.1089/ars.2013.5576. 


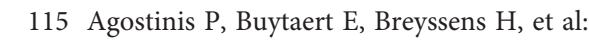
Regulatory pathways in photodynamic therapy induced apoptosis. Photochem Photobiol Sci 2004;3:721-729.

116 Oleinick NL, Evans HH: The photobiology of photodynamic therapy: cellular targets and mechanisms. Radiat Res 1998;150:S146S156.

-117 Engelmann FM, Rocha SVO, Toma HE, et al: Determination of $n$-octanol/water partition and membrane binding of cationic porphyrins. Int J Pharm 2007;329:12-18.

118 Uzdensky AB: Signal transduction and photodynamic therapy. Curr Signal Transduct Ther 2008;3:55-74.

-119 Liu T, Wu LY, Berkman CE: Prostate-specific membrane antigen-targeted photodynamic therapy induces rapid cytoskeletal disruption. Cancer Lett 2010;296:106-112.

120 Stockert JC, Juarranz A, Villanueva A, et al: Photodynamic damage to HeLa cell microtubules induced by thiazine dyes. Cancer Chemother Pharmacol 1996;39:167-169.

121 Mroz P, Yaroslavsky A, Kharkwal GB, et al: Cell death pathways in photodynamic therapy of cancer. Cancers (Basel) 2011;3:25162539.

-122 Almeida RD, Manadas BJ, Carvalho AP, et al: Intracellular signaling mechanisms in photodynamic therapy. Biochim Biophys Acta 2004;1704:59-86.

123 Wu S, Zhou F, Wei Y, et al: Cancer phototherapy via selective photoinactivation of respiratory chain oxidase to trigger a fatal superoxide anion burst. Antioxid Redox Signal 2014;20:733-746.

124 Buytaert E, Dewaele M, Agostinis P: Molecular effectors of multiple cell death pathways initiated by photodynamic therapy. Biochim Biophys Acta 2007;1776:86-107.

125 Oleinick NL, Morris RL, Belichenko I: The role of apoptosis in response to photodynamic therapy: what, where, why, and how. Photochem Photobiol Sci 2002;1:1-21.
126 Benov L, Craik J, Batinic-Haberle I: The potential of $\mathrm{Zn}$ (II) N-alkylpyridylporphyrins for anticancer therapy. Curr Med Chem Anticancer Agents 2011;11:233-241.

127 MacDonald IJ, Dougherty TJ: Basic principles of photodynamic therapy. J Porphyr Phthalocyanines 2001;5:105-129.

128 François A, Salvadori A, Bressenot A, et al: How to avoid local side effects of bladder photodynamic therapy: impact of the fluence rate. J Urol 2013;190:731-736.

129 Henderson BW, Gollnick SO, Snyder JW, et al: Choice of oxygen-conserving treatment regimen determines the inflammatory response and outcome of photodynamic therapy of tumors. Cancer Res 2004;64:21202126.

130 Mendoza J, Sebastian A, Allan E, et al: Differential cytotoxic response in keloid fibroblasts exposed to photodynamic therapy is dependent on photosensitiser precursor, fluence and location of fibroblasts within the lesion. Arch Dermatol Res 2012;304:549562.

131 Ibbotson SH, Ferguson J: Ambulatory photodynamic therapy using low irradiance inorganic light-emitting diodes for the treatment of non-melanoma skin cancer: an open study. Photodermatol Photoimmunol Photomed 2012;28:235-239.

132 Rogers GS: Continuous low-irradiance photodynamic therapy: a new therapeutic paradigm. J Natl Compr Canc Netw 2012;10:S14-S-17.

$\checkmark 133$ Zeitouni NC, Paquette AD, Housel JP, et al: A retrospective review of pain control by a two-step irradiance schedule during topical ALA-photodynamic therapy of non-melanoma skin cancer. Laser Surg Med 2013;45: 89-94.

134 Ochsner M: Photophysical and photobiological processes in the photodynamic therapy of tumours. J Photochem Photobiol B 1997;39:1-18.
135 Ibbotson SH: Adverse effects of topical photodynamic therapy. Photodermatol Photoimmunol Photomed 2011;27:116-130.

136 Attili SK, Dawe R, Ibbotson S: A review of pain experienced during topical photodynamic therapy - our experience in Dundee. Photodiagnosis Photodyn Ther 2011;8:5357.

137 Nyst HJ, Tan IB, Stewart FA, et al: Is photodynamic therapy a good alternative to surgery and radiotherapy in the treatment of head and neck cancer? Photodiagnosis Photodyn Ther 2009;6:3-11.

138 Wilson BC, Patterson MS: The physics, biophysics and technology of photodynamic therapy. Phys Med Biol 2008;53:R61-R109.

139 Silva EFF, Schaberle FA, Monteiro CJP, et al: The challenging combination of intense fluorescence and high singlet oxygen quantum yield in photostable chlorins-a contribution to theranostics. Photochem Photobiol Sci 2013;12:1187-1192.

140 Stefflova K, Chen J, Zheng G: Killer beacons for combined cancer imaging and therapy. Curr Med Chem 2007;14:2110-2125.

141 Monnereau C, Gallavardin T, Armagnat C, et al: Two-photon absorbing chromophores for photodynamic therapy: molecular engineering and in vivo applications. Proceedings SPIE, San Diego, 2011, article 81030N.

142 Fowley C, Nomikou N, McHale AP, et al: Extending the tissue penetration capability of conventional photosensitisers: a carbon quantum dot-protoporphyrin IX conjugate for use in two-photon excited photodynamic therapy. Chem Commun (Camb) 2013; 49:8934-8936.

143 Mathews MS, Angell-Petersen E, Sanchez R, et al: The effects of ultra-low fluence rate single and repetitive photodynamic therapy on glioma spheroids. Lasers Surg Med 2009;41: 578-584.

144 Moghissi K: PDT: the plight. Photodiagnosis Photodyn Ther 2007;4:223-223. 